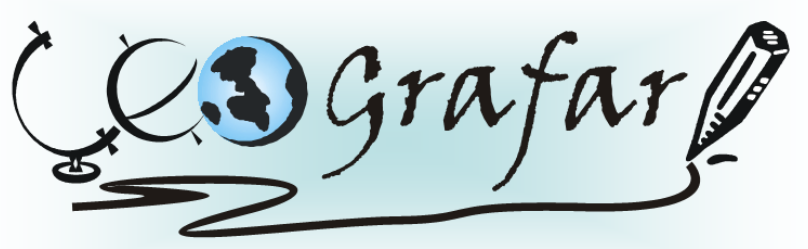

Revista Eletrônica do Programa de Pós-Graduação em Geografia - UFPR

\title{
A CAÇADA DA RAINHA EM COLINAS DO SUL: UM DIÁLOGO ENTRE LUGAR E IDENTIDADES
}

\section{THE QUEEN OF THE HUNT IN COLINAS DO SUL: A DIALOGUE BETWEEN PLACE AND IDENTITY}

(Recebido em 29.06.2015; Aceito em: 14.03.2016)

\author{
Isabella de Faria Bretas \\ Doutoranda em História \\ Universidade Federal de Goiás \\ Goiânia, GO, Brasil \\ e-mail: isabella.bretas@gmail.com \\ Maria Geralda de Almeida \\ Prof ${ }^{a}$. Dr ${ }^{a}$ do Dep. de Geografia \\ Universidade Federal de Goiás \\ Goiânia, GO, Brasil \\ e-mail:mgdealmeida@gmail.com
}

\section{RESUMO}

A Caçada da Rainha é uma manifestação cultural que ocorre, de maneira mais tradicional, no município de Colinas do Sul no Estado de Goiás e faz referência à época do Império Brasileiro. Os participantes se vestem de acordo com suas funções, cujas principais são: rei, rainha, imperador, soldado da guarda real entre outros. No presente artigo defende-se que essa festa, por meio dos laços dos moradores com seus símbolos, signos e representações, que passam a demarcar uma cultura singular da festividade no Estado, caracteriza a presença do lugar e por isso necessita ser identificada e espacializada. Por meio da Geografia Cultural, as manifestações culturais ganham força devido à nova abordagem sobre os sujeitos (festivos) e seus costumes, discutindo o diferente, as particularidades e os modos de representação. A importância da Caçada da Rainha está centrada na análise dos significados e o objetivo é compreendê-la nessa perspectiva. É também investigar como essa festa atua na transformação do espaço em lugar e na criação de identidades de lugar e dos sujeitos partícipes. Para a realização de tais finalidades a metodologia centrou-se no embasamento teórico e na pesquisa de campo, o que possibilitou a identificação de símbolos, sentimentos, emoções e sensações dos 
sujeitos. Nesse sentido refletiu-se, também, sobre a dimensão humana e sua ligação com o meio, essencial para identificar a Caçada da Rainha enquanto fator de interação entre sujeito e espaço configurado como lugar.

Palavras-chave: lugar; identidade; cultura.

\begin{abstract}
The "Queen of the Hunt" is a cultural event that takes place in a more traditional way, in the municipality of Colinas do Sul in the state of Goiás and refers to the time of the Brazilian Empire. Participants dress in accordance with their duties, the main are: king, queen, emperor, soldier of the royal guard and others. In this article we argue that the party, through ties of residents and their symbols, signs and representations that come to demarcate a unique culture of the festival in the state, featuring the presence of the place and so needs to be identified and spatialized. Through the Cultural Geography, cultural events gain strength characterized by fresh take on the festive subjects and their customs, discussing the different, the circumstances and modes of representation. Its importance is focused on the analysis of the meaning and the goal is to understand a traditional festival that perspective. It is also investigating how this ritual acts in the transformation of the space in place and creating instead of identities and participants subject. For the achievement of such goals the methodology focused on the theoretical basis and field research that enabled the identification of symbols, feelings, emotions, feelings and meanings of the subject. In this sense was reflected also on the human dimension and its connection with the environment, essential to identify the "Queen of the Hunt" as a fact of interaction between subject and space set to place.
\end{abstract}

Keywords: place; identity; culture.

\title{
INTRODUÇÃO
}

Nas considerações propostas por este artigo, o objetivo é refletir a dimensão humana e sua ligação afetiva com o espaço, fator responsável pela construção de identidades tanto dos sujeitos quanto dos lugares aos quais estes se sentem pertencentes. Nesse sentido o enfoque é na festa denominada "Caçada da Rainha" como manifestação cultural que deve ser analisada enquanto fator de interação entre o sujeito e o meio. Na Geografia o discurso pós-moderno se apóia na associação entre pensamento e ação geográficos, como diz Almeida (2013):

[...] em uma perspectiva mais ampla, ele [discurso pós-moderno] é constituído do dimensionamento e da humanização da superfície terrestre, ambiente profundamente transformado e organizado pelo homem. Discurso 
e prática geográficos são simbióticos. Fazem com que seja ilusório considerar como dissociadas uma história do pensamento geográfico e uma história da ação geográfica, mesmo se é frequentemente necessário concentrar-se separadamente sobre as questões que elas produzem (p. 44)

A Caçada da Rainha deve ser compreendida por meio dessa junção entre fatores porque é resultante da relação entre sujeitos e o meio aonde acontece. Ela ocorre no município de Colinas do Sul, localizado entre a Chapada dos Veadeiros e o lago Serra da Mesa na porção norte do Estado de Goiás. O presente artigo defende que a festa caracteriza a presença do lugar festivo e das identidades por meio dos laços dos moradores com seus símbolos, signos e representações que passam a demarcar uma cultura singular da festividade no Estado e, por este motivo necessita ser identificada e espacializada.

Para a realização das finalidades propostas a metodologia centrou-se no levantamento bibliográfico para base teórica e na pesquisa de campo com o intuito de analisar o cotidiano festivo e não festivo da comunidade. Assim, foi possível identificar os laços entre os sujeitos e deles com o lugar, apreendendo símbolos, significados, sentimentos e conflitos. Utilizando-se de entrevistas qualitativas baseadas no Diagnóstico Rural Participativo (DRP), houve a possibilidade de um contato direto com os participantes da festa, além de identificar aspectos específicos de cada grupo presente na manifestação. O conteúdo das entrevistas girou em torno do assunto sobre o sentimento dos sujeitos em relação ao lugar da festa e suas representações. Então, foi possível analisar os vínculos afetivos e a identificação dos partícipes com o espaço festivo.

\section{MÉTODO}

Inicialmente, a discussão será em relação ao espaço festivo e como este se transforma em lugar à medida que é dotado de sentimentos e valores pelos partícipes da Caçada da Rainha. Geógrafos conceituados auxiliam nesse propósito ao abordarem essa categoria enquanto análise subjetiva da relação entre o sujeito e o seu meio. Em um segundo momento, haverá uma breve explanação do que é a festa, das histórias lendárias que permeiam o imaginário popular de Colinas do Sul e os seus sujeitos festivos. Serão discutidas, ainda, as identidades dos grupos e as 
identidades dos lugares pois estão ligadas umas às outras e todas influenciam e são influenciadas pela prática festiva.

Para a realização de tais objetivos adotou-se procedimentos metodológicos específicos resumidos em três etapas que, em muitos momentos, ocorreram simultaneamente. A primeira delas, cujo embasamento se dá, principalmente na Antropologia, foi a visita a campo, na comunidade em que ocorre a festa referida, tanto em momentos festivos quanto não festivos. O intuito era apreender as crenças e os valores os quais levam as pessoas a realizarem a manifestação, considerando o fato de que a mesma possui uma base religiosa. A segunda etapa foi a participação efetiva na festa, nos preparativos iniciais como a organização de barraquinhas, o ornamento da Igreja e do espaço festivo, a preparação dos cavalos que seriam utilizados para a "caça" à rainha, entre outros. Nesse momento a ideia era apreender as atividades cotidianas dos partícipes, conquistando a confiança e amizade dos mesmos, além de se tornar "parte" da festa enquanto auxiliar da organização. A terceira etapa aqui enumerada, ressaltando o fato de que estão exemplificadas apenas aquelas consideradas mais relevantes para a confecção do presente artigo, foi a realização de entrevistas semiestruturadas com participantes, moradores da comunidade e visitantes. Este procedimento metodológico possui respaldo em Dencker (2000) que exemplifica o método adotado e defende uma maior liberdade dos entrevistados para responderem e se posicionarem diante dos questionamentos.

\section{RESULTADOS E DISCUSSÕES}

\section{O espaço transformando-se em lugar}

O espaço geográfico, para alguns geógrafos, como Ferreira (2000), Almeida (2011), Tuan (1983) e Holzer (1999), é concebido como um espaço existencial imbuído de sentimentos, laços de afetividade, emoções e significados. Tal concepção confere ao espaço uma característica de lugar atribuindo-lhe símbolos próprios e conferindo-Ihe uma identidade por meio da apropriação dos sujeitos. Repleto de imaterialidades reveladas pelas paixões, conflitos, risos e encantamentos, esse sentido de lugar revela-se tal como descreveu Terra (2005), ao 
apresentar as percepções e vivências responsáveis pelos laços afetivos do sujeito com o seu espaço:

Quando criamos uma identidade com o lugar em que vivemos, ele é algo para nós, nossa memória guarda sobre ele percepções e vivências com as quais nos identificamos. Portanto, estabelecemos com o lugar uma relação de afetividade (p. 5).

Esta é uma perspectiva inovadora proposta pelos adeptos da Geografia Humanista que estabelecem uma relação entre a racionalidade e o sentimento e cujos pontos de partida legítimos para a explicação dentro dessa ciência são o espaço e a população. Essa abordagem pós-modernista, que ganhou força por volta de 1980, "não se caracteriza pelo seu objeto que aborda e sim pela maneira pela qual ela o trata" (ALMEIDA, 2013, p.44) e, dessa forma, pretende-se direcionar uma visão diferenciada, por meio da sensibilidade, a um conjunto de pessoas que pratica suas atividades culturais. Essa tendência favorece atenção às emoções, aos sentimentos e às sensações como fontes de conhecimento, essenciais à compreensão da organização humana no que se refere à identidade.

Com o homem, enquanto sujeito e ator social, colocado no centro, surgem pesquisas que argumentam que o subjetivo e o objetivo não devem ser entendidos como distintos, pelo contrário. Nesse sentido Holzer (2010) enfatiza:

[...] os temas potencialmente exploráveis pela Geografia: a intencionalidade do homem na estruturação de seu mundo (intencionalidade do corposujeito); e a intersubjetividade, definida como o diálogo entre o homem e o meio, em termos de herança sociocultural e do papel assumido por ele no mundo vivido (p. 40).

Compreender os "lugares" é entender as relações humanas e as relações entre os sujeitos e a natureza, sua estruturação é relevante para a constituição das práticas socioculturais e religiosas que se estabelecem. A Geografia Humanista, com base nos autores já citados, possibilita ao geógrafo uma maior apreensão de como os homens criam lugares, atribuindo significado ao espaço e de como isso favorece a construção das identidades naquele espaço. Essa perspectiva defende a necessidade de valorizar a experiência do sujeito ou do grupo na busca da compreensão da sua forma de sentir, das pessoas em relação aos seus lugares. 
Um dos autores utilizado e contribuinte de uma perspectiva inovadora na geografia, que propõe ao geógrafo uma maior e melhor apreensão das relações que os homens mantêm com seu entorno, foi Tuan (1983). Ele define o lugar enquanto experiência de um espaço vivido e, portanto, marcado por valores, símbolos e significados, para as pessoas que nele vivem. Ao se referir ao lugar 0 autor expressa:

[...] todos os lugares são pequenos mundos (...) ele é uma entidade única, um conjunto especial, que tem história e significado (...) um centro gerador de significados geográficos, que está em relação dialética com o construído abstrato que denominamos espaço (TUAN, 1983, p. 149).

Almeida (1993) compartilha com a ideia de uma ciência voltada mais para a percepção, para a análise do sentimento envolvido, da experiência e das crenças do sujeito. Esses pontos devem ser considerados ao estudar o espaço geográfico. Elucidando tal perspectiva, do ponto de vista da Geografia Humanista, o experimentador vive, desloca-se e busca um significado. Dessa forma, o espaço ultrapassa sua condição, ao ser alçado ao patamar de lugar ou de lar, um universo no qual as coisas e pessoas possuem valor devido às experiências cotidianas e aos elos que as unem com o ambiente. Essas experiências vividas pelos sujeitos e grupos sociais contemplam a maneira de agir, bem como sentimentos, projeções, angústias, entendimentos e delírios das pessoas em relação aos seus lugares.

Dotado, portanto, de uma expressão coletiva, o lugar como "somatório das dimensões simbólicas, emocionais, políticas, culturais e biológicas" (BUTTIMER, 1985, p. 228) tornou-se o conceito-chave da ciência geográfica na dimensão humanista. Tuan (1983) acrescenta que os lugares, assim como os objetos, são núcleos de valor e podem ser totalmente apreendidos por meio de uma experiência que engloba relações íntimas. O lugar torna-se realidade, portanto, por meio da familiaridade entre sujeito e espaço, a partir do momento em que é dotado de significado. Este (o espaço) "transforma-se em lugar à medida que o conhecemos melhor e o dotamos de valor" afirma Tuan (1983, p.6).

Ainda no campo da Geografia Humanista, é perceptível que sua linha de pensamento caracteriza-se, principalmente, pela valorização das relações de afetividade desenvolvidas pelos sujeitos em relação ao seu ambiente. Para os seguidores dessa corrente, o lugar, é um produto da experiência humana: "(...) lugar 
significa mais que o sentido geográfico de localização. Não se refere a objetos e atributos das localizações mas a tipos de experiência e envolvimento com o mundo, a necessidade de raízes e segurança" (RELPH, 1979, p. 25). Ou ainda, citando Tuan (1975, p. 152) novamente, "lugar é um centro de significados construído pela experiência". Ele é carregado de sensações emotivas principalmente porque nos sentimos seguros e protegidos, na concepção de Mello (1990).

Relph (1979) para explicar a relação de pertencimento e afetividade com o espaço, toma como base teórica o mundo vivido que:

[...] é simplesmente o mundo de espaços, paisagens e lugares, o qual todos devemos encontrar em nossas vidas diárias [...] os espaços com os quais somos estreitamente familiares, são diferenciados daqueles com os quais temos apenas uma familiaridade passageira (p. 36).

Todo sujeito está rodeado por espaços vividos que podem ser considerados, em sua maioria, lugares, como a igreja, a escola, um bar ou uma discoteca. Para que se torne lugar é necessário conhecer o espaço intimamente, de maneira que se possa identificá-lo, reconhecê-lo e interpretá-lo por todos os sentidos humanos. São, portanto, os sujeitos os responsáveis por transformarem o espaço em lugar. Nessa perspectiva a ciência geográfica proporciona uma "melhor apreensão das relações que os homens mantem com seu entorno, de como eles criam lugares, de como atribuem um significado ao espaço e dão um sentido de lugar a ele" (ALMEIDA; VARGAS; MENDES, 2011, p. 24).

Durante a realização da Caçada da Rainha, os sujeitos que criam, organizam e participam, geralmente moradores de Colinas do Sul, vivenciam aquele acontecimento, se sentem parte dos vários rituais existentes. Uma vez questionados, disseram que "Colinas do Sul não existe sem a Caçada da Rainha" (Z.M. e M.S. entrevistados em julho de 2013, em Colinas do Sul) o que mostra o forte vínculo entre a festa e os moradores.

\section{Caçada da Rainha: uma breve explanação}

Essa manifestação da cultura é uma encenação teatral que parece se reportar ao tempo do Império Brasileiro e é também uma celebração que merece destaque por ser tradicional e antiga no município estudado do Estado de Goiás. Em Colinas 
do Sul, a narrativa contada pela população local refere-se ao fato de a princesa Isabel, aproveitando-se da ausência do pai que estava em uma viagem para Portugal, ter assinado a Lei Áurea determinando a libertação de negros mantidos como escravos.

Apreensiva e com medo da represália de Dom Pedro II, ela fugiu para a floresta junto com seus acompanhantes e, quando o imperador voltou de viagem, decidiu procurá-la levando consigo a guarda real. Depois de algum tempo de busca a encontraram e então as pessoas juntaram-se em uma única celebração: os exescravos por terem sido de fato libertos, uma vez que Dom Pedro aceitou a decisão da filha, o imperador por ter encontrado a princesa, e ela por constatar que o seu feito gerou orgulho em seu pai.

O interessante é a encenação que os participantes da festa realizam para "vivenciar" a história acima. Eles são, geralmente, escolhidos por sorteio e devem se vestir para representarem os protagonistas da história: o imperador, os soldados da guarda real e a "rainha" que faz referência à princesa Isabel, entre outras figuras. A rainha é escondida na mata cerradeira e a guarda real, ou qualquer outro partícipe da festa, deve procurá-la.

Enquanto ocorre a busca, mulheres negras dançam um ritmo denominado "Sussa" ou "Sucia" que, segundo moradores e a vivência em campo, corresponde a um batuque animado. As dançarinas representam as mulheres negras escravizadas comemorando sua alforria naquele momento. Assim como elas, existem os "congos", homens negros que cantam e dançam um ritmo também peculiar. Nas missas que ocorrem nesse dia eles não podem adentrar a Igreja porque, mesmo depois da escravidão, negros e brancos não ocupavam o mesmo espaço e a instituição religiosa era frequentada, predominantemente, pela elite branca.

Muitas vezes quem encontra a rainha ganha um prêmio em dinheiro como forma de incentivar as pessoas a participarem mais do festejo, para que a tradição continue acontecendo. A manifestação perpetua-se, porém com a ressignificação de seu significado inicial e de seu lugar. A todo o momento existem comportamentos humanos diferentes daqueles que, supostamente, originaram a celebração. Referese aqui ao dinamismo da cultura popular. Em contrapartida a festa é criadora das novidades e independente do seu papel social cria também um espaço singular, cujas particularidades vão se moldando ao longo das próprias ocorrências, 
ajustando-se aos atores e seus símbolos, valores, crenças e leis, fazendo com que o pluralismo cultural seja ainda a principal característica do povo brasileiro.

Os detalhes de como esses personagens da festa se apropriam e vivem 0 lugar em Colinas do Sul permitem traçar, em partes, os contornos das identidades dos sujeitos que compõem a Caçada da Rainha.

\section{Os sujeitos festivos de Colinas do Sul}

O município em questão destaca-se em âmbito estadual durante o período festivo da Caçada da Rainha cujos principais sujeitos da festa são os próprios moradores da comunidade. É possível vê-los decorando o local e protagonizando as atividades que envolvem o festejo como a confecção dos uniformes e a divulgação dos rituais que se estendem ao longo de quatro dias.

A rainha e o rei são diretamente responsáveis pelo que acontece durante esse período, desde os giros das folias, nos quais devem estar presentes em alguns momentos tidos como principais, até os shows de artistas consagrados que atraem o público dos municípios vizinhos. Nesse sentido, a "Caçada" é uma festa tipicamente de caráter popular porque sem a atuação dos chamados "festeiros" ela não ocorre e os órgãos públicos configuram um estímulo secundário, nem sempre essencial. Financeiramente, os reis auxiliam na contratação dos artistas e no levantamento do palco mas a comunidade é, de fato, a grande responsável pelo acontecimento. Ao se unirem em um só objetivo, os sujeitos se ajudam mutuamente com doações de alimentos para os almoços e jantares dos foliões e dos reis, com a confecção de roupas para eles próprios representarem seus papéis na festa e, com a organização da manifestação festiva.

A Igreja atua no que se refere aos rituais religiosos como levantamentos de mastros e celebrações de missas para a rainha e para o rei, mas, também, não é essencial. Não existe intervenção de associações ou participação relevante de secretarias ou órgãos ligados ao governo. O fato é que estes somente "ditam as regras" mas quem organiza são os moradores, os mesmos que atuam e participam da festa.

Os foliões, que se identificam como "foliões da rainha" representam esse papel há muitos anos e, geralmente, pertencem a famílias tradicionais cujo costume 
já é repassado por gerações. Possuem determinadas responsabilidades como os alferes das bandeiras e essas funções são permanentes. Juntamente com outros organizadores decidem anualmente o trajeto a ser percorrido pelos dois grupos de folias existentes e a mudança em seus uniformes depende exclusivamente da vontade do rei e da rainha.

Um mesmo sujeito pode atuar em vários momentos da festa. É o caso de alguns foliões que também são participantes do grupo dos congos. Esse fato comprova o caráter popular da "Caçada" pois, além de serem organizadores, os moradores são, também, os que participam e realizam os rituais mesmo que isso signifique assumir diversos papéis ao longo dos quatro dias. Os reis e rainhas além de serem personagens da realeza são os que atuam financeiramente para arrecadação de doações, são festeiros e são organizadores. Enfim, a participação da comunidade em Colinas do Sul é o que caracteriza o lugar da Caçada da Rainha, transformando-o em um ambiente familiar.

\section{As identidades dos grupos, as identidades do lugar}

O sujeito só pode ser compreendido a partir da relação do indivíduo e sua cultura, fazendo com que sua identidade não seja algo fixo, definido por uma essência mas sim criada constantemente. Destaca-se que a abordagem da identidade associada ao espaço/lugar deve ser entendida por meio do pressuposto apontado por Garcia Canclini (2006, p. 217), ao enfatizar que esta é "[...] uma construção imaginária que se narra". Assim, a identidade, de fato, é uma construção, mas "[...] o relato artístico, folclórico e comunicacional que a constitui se realiza e se transforma em relação a condições sócio-históricas”. É delineada, simultaneamente, por materialidades e imaterialidades, aspectos objetivos e subjetivos, permanências e rupturas. Nesse sentido, o sujeito é formado e modificado num diálogo contínuo com os mundos culturais "exteriores" e as identidades que esses mundos oferecem. Dessa forma a constituição do sujeito está mediada pelas relações com as pessoas, os valores, os sentidos, os símbolos, as culturas. O sujeito vai se constituindo à medida que internaliza valores e significados que permeiam o social, fazendo com que a natureza de sua identidade seja múltipla. 
Essa ideia desconstrói a teoria do sujeito racional com noções de verdades inquestionáveis e absolutas, na medida em que coloca o homem como ser em constante processo de formação. Isso implica na superação da abordagem do sujeito que teria um núcleo interior permanecendo essencialmente o mesmo contínuo ou idêntico a ele - ao longo da existência do indivíduo.

Na Caçada da Rainha, entende-se que a linguagem, o movimento, o cântico e outras representações participam no processo de identificação porque define a identidade do sujeito quando ele se relaciona com o outro. Fator que é mutável porque em períodos não-festivos os sujeitos já não são mais identificados como foram durante a festa. A identidade está relacionada com o meio, o que lhe confere a capacidade de variáveis articulações.Ao afirmar que a identidade é móvel, indicase a possibilidade de compreender, de maneira mais significativa, as representações que formam (e transformam) as culturas, os sujeitos e os espaços. O sujeito nessa perspectiva é constituído por representações as quais são mutáveis e as certezas se desfazem.

Atentando para o que Hall (2006) propõe, um sujeito detentor de várias identidades, foi possível verificar na festa da Caçada da Rainha essa multiplicidade. O folião, que gira aproximadamente por 15 dias na zona rural do município, homenageando a Nossa Senhora do Rosário e o Divino Espírito Santo, e convidando as pessoas para participarem da "Caçada", compõe também a guarda real que sai a procura da rainha. A festeira, que oferece comida e o pouso à Folia, pode ser também uma dançarina da "Sussa", que se apresentará à tarde enquanto a rainha estiver desaparecida. Diversos são os personagens incorporados pelos sujeitos e mais numerosos ainda são os rituais durante a ocorrência da manifestação, o que é um dos fatores que caracteriza a festividade em Colinas do Sul e confere uma identidade ao espaço festivo.

Ao falar sobre identidade do lugar, pressupõe discorrer sobre a intenção humana, pois os lugares só adquirem identidade e significado por meio dessa intenção e da relação existente entre os sujeitos e os atributos objetivos do lugar, ou seja, o cenário físico e as atividades ali desenvolvidas. Tuan (1983, p. 42) afirma, neste sentido, que precisamos conhecer "a qualidade e a intensidade da experiência" do homem com o ambiente para o conhecimento da identidade do lugar 
e, desta forma, introduz o conceito de topofilia que tem sua aplicação na análise da afetividade pelo lugar.

O processo de construção das identidades, de acordo com Claval (2003, p. 92) implica na "interiorização de valores" portanto, à luz dessa reflexão é possível concluir que a identidade de um lugar não pode ser desassociada das raízes dos que o habitam. Almeida (2008, p. 317) complementa dizendo que "é pela cultura que essas populações fazem sua mediação com o mundo, constroem um modo de vida particular e se 'enraizam' ".Com base nos dois autores, reconhece-se a contribuição do estudo da Caçada da Rainha para percepção da identidade do lugar, o que este representa para cada grupo partícipe da festa e como recebe características próprias de cada um.

A identidade, o sentimento de pertencimento e o acúmulo de tempos e histórias individuais constituem o lugar que guarda em si o seu significado e as dimensões do movimento da história, apreendido pela memória, por meio dos sentidos. Nessa perspectiva não é possível dissociar a identidade do sujeito com o local no qual ele reside e vice-versa

O entendimento de identidade de lugar deve necessariamente compreender a relação do sujeito com os espaços e lugares sendo que essa relação constitui o mecanismo de significação do próprio sujeito em interação com pessoas e lugares. Com a intenção de fortalecer o debate proposto, recorre-se a proposta de identidade de lugar de Proshansky, Fabian \& Kaminoff (1983) que afirmam que:

\footnotetext{
a identidade de lugar dos distintos grupos de uma cultura deve revelar não só usos e experiências diferentes do espaço e lugar, mas variações correspondentes aos valores sociais, significados e idéias que estão subjacentes aos usos daqueles espaços (p. 64).
}

Eles sustentam ainda que os aspectos ambientais e o entorno físico proporcionam o desenvolvimento e a manutenção da identidade social. Esta ideia exemplifica o fato dos carros com sons automotivos presentes na festa pertencerem aos visitantes e não aos moradores que ainda estão vinculados a um estilo de vida com características mais rurais. Dessa maneira, as diferentes identidades existentes na festa são representadas por elementos próprios de cada grupo e que, por sua vez, caracterizam uma identidade espacial que engloba todas essas relações entre os sujeitos e a Caçada da Rainha. 
A dimensão espacial desse evento festivo envolve também significações conferidas aos diversos símbolos expressos em desenhos e demais inscrições que fazem parte dos dois grupos de Folias existentes e mencionados anteriormente e outros que estão presentes no espaço urbano. Os foliões passam por volta de quinze dias nas fazendas e carregam simbologias e costumes responsáveis pela caracterização da identidade espacial. Os trechos percorridos durante os diversos momentos da festa, as alvoradas e deslocamentos de uma residência a outra, além da estrutura coreográfica são exemplos de como o movimento, em decorrência dos rituais festivos, atribui valor e significado ao espaço. A festa, nesse sentido, é um evento eminentemente de deslocamentos e a lógica de organização de cada grupo tem sentido espacial, uma vez que modificar os posicionamentos dos membros dentro da estrutura já estabelecida é atribuir-Ihe um significado diferente daquele ao que está adaptado.

A figura abaixo (Figura 1) demonstra como a chegada dos foliões na zona rural transforma a dinâmica espacial e como o espaço é dotado de valor e significado nesse momento.

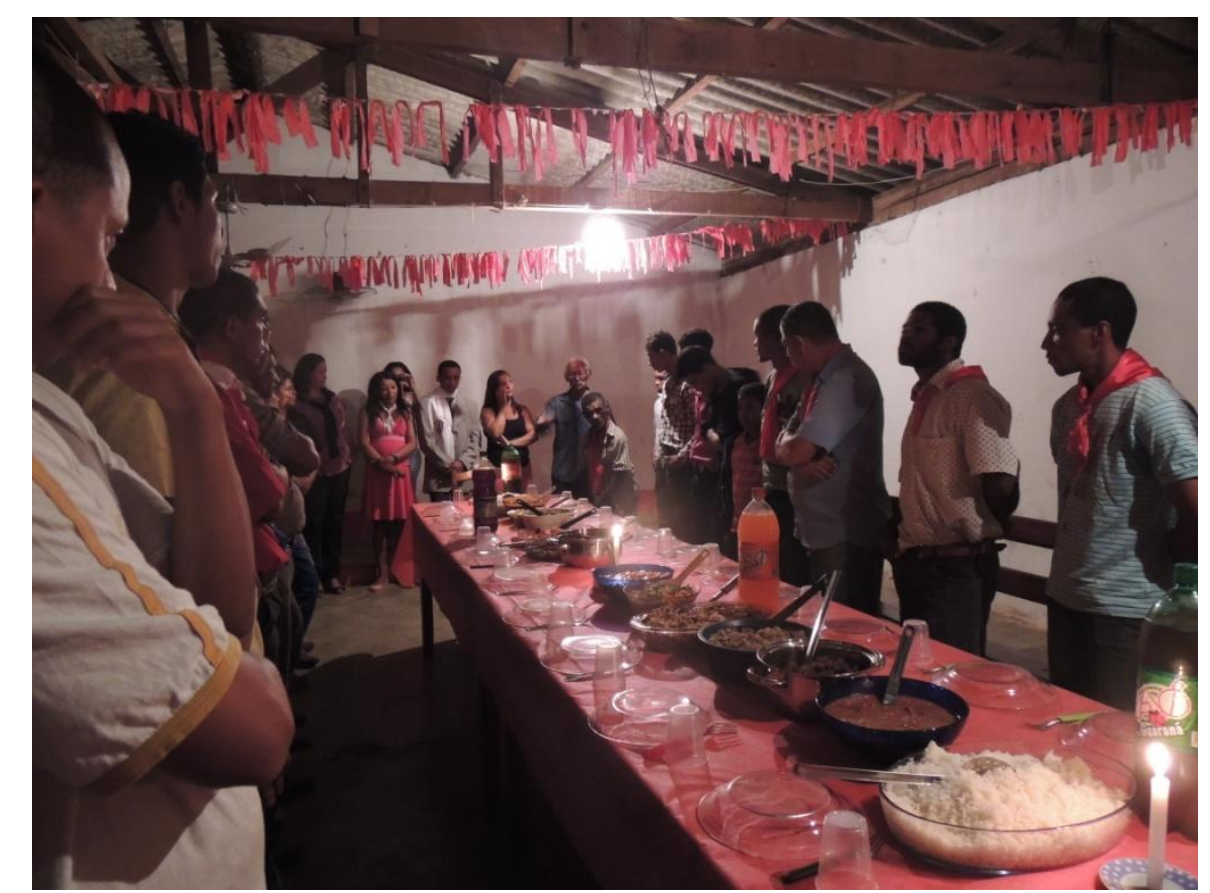

Figura 1: Foliões ao redor da mesa ouvindo o folião mais antigo (autoria: $\mathrm{O}(\mathrm{a})$ autor(a). Julho, 2014)

A Caçada da Rainha em Colinas do Sul abrange uma série de espaços, cada um com características próprias e alguns são elevados a categoria de lugar e the é 
conferida uma identidade por grupos distintos. No que se refere às Folias, os moradores e receptores dessa prática religiosa se apropriam do espaço rural, bem como das residências inseridas nele, e o transformam em lugar quando demonstram sentimentos significativos como a devoção, a solidariedade entre os sujeitos e a ideia de raiz e vínculo com a terra. As espacialidades, também, são expressas por meio das músicas entoadas pelos foliões e demais participantes da festa no espaço urbano. Elas fazem referências e alusões à rainha que fugiu e ao rei que foi procurála. Entende-se, pois, que o ato de festejar teria por si só, uma dimensão espacial, pois, estar inserido em um dado espaço e concebê-lo como festivo por meio de ações e apropriações, já caracterizaria uma movimentação no espaço.

Mais um momento dos foliões e o espaço festivo podem ser observados abaixo (Figura 2), quando eles estão tocando em homenagem às divindades católicas.

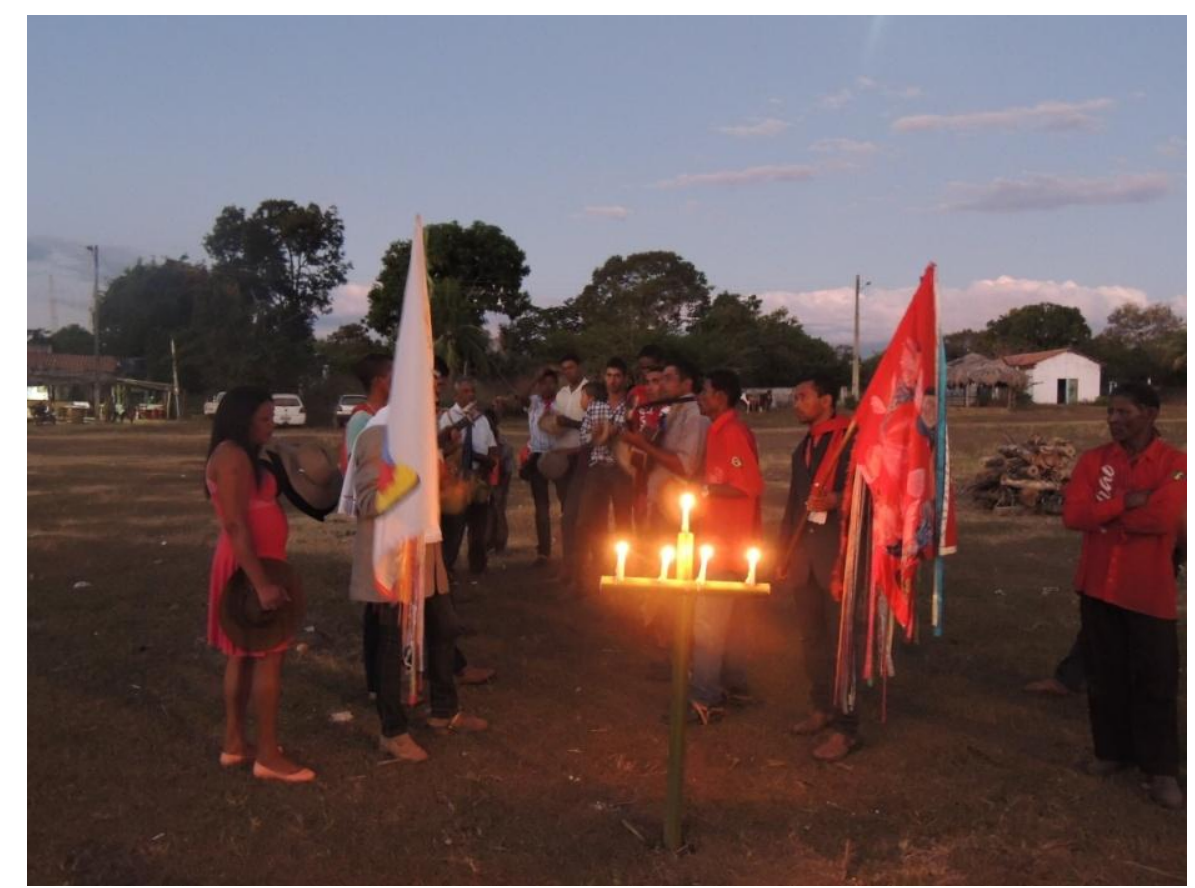

Figura 2: Grupo de Folia no Povoado de Lajes, Colinas do Sul (autoria: O(a) autor(a). Julho, 2014)

Enfim, como é possível notar na imagem acima, este estudo concede conhecimento e aprendizagem sobre aspectos das relações humanas e do espaço geográfico habitado e vivenciado. Os sujeitos o visitam e se apropriam, criando um lugar único, repleto de subjetividades. 


\section{CONCLUSÃO}

A Geografia contemporânea propicia leituras amplas e diferenciadas no que se refere às categorias geográficas e suas relações com o sujeito, abrangendo a subjetividade e dando visibilidade aos grupos cujas vozes, até então, estavam "silenciadas".

Devido a este fato constatou-se a festa como promotora de identidades de sujeitos e lugares, uma vez que é a expressão de grupos minoritários. No que se refere a Colinas do Sul, a festa Caçada da Rainha, fornece meios para que sujeitos comuns ganhem destaque por um dia, representando reis, guardas, e demais personagens elitizados. "O espaço geográfico, apropriado simbolicamente, constitui parte fundamental dos processos de identificação social" (LIMA, 1998, p. 165), por meio deste pensamento resumido na frase da autora entende-se o espaço festivo como essencial para a compreensão das identidades dos sujeitos do município estudado.

O enraizamento de sentimentos, a assimilação e a consequente incorporação da cultura local contribuem para a formação de identidades e de lugares. Por isso, acredita-se na importância do estudo da Caçada da Rainha para compreender a realidade e o sentido da festa para os partícipes e moradores. Além disso os símbolos evidenciados nas figuras demonstradas ao longo deste contribuíram para a compreensão da identidade dos sujeitos e do espaço transformado em lugar devido às emoções e sentimentos atribuídos a ele durante a manifestação. Para quem não vivencia o espaço festivo cotidianamente torna-se complexo compreender os elementos característicos do festejo que the atribuem valor, como os variados símbolos religiosos e rituais ligados à história do município e do povo que nele habita. A utilização da memória, nesse ponto, foi fundamental para entendimento dessa história e, inclusive, do surgimento da "Caçada da Rainha". Buscou-se aprofundar o conhecimento a respeito do surgimento e da manutenção da tradição, como essa se respalda na realidade, por meio de uma memória que a sustenta e solidifica.

A festa mencionada é criadora de lugar e de identidades e, nessa perspectiva, atua e influencia diretamente nos sentimentos dos sujeitos enquanto pertencentes ao espaço festivo. Ela abrange uma série de espaços, cada um com características 
próprias e ainda elevados a categoria de lugar, ao the serem conferidos valor e sentido por grupos distintos.

\section{Referências}

ALMEIDA, Maria Geralda de. Geografia Cultural e Geografos Culturalistas: Uma Leitura Francesa. Geosul (UFSC), v. 14, p. 35-47, 1993.

Diversidades paisagísticas e identidades territoriais e culturais do

Brasil sertanejo. In: ; CHAVEIRO Eguimar Felício; BRAGA, Helaíne Costa (orgs.). Geografia e Cultura: os lugares da vida e a vida dos lugares. Goiânia: Vieira, 2008. p. 47 - 74.

; VARGAS, Maria Augusta Mundim; MENDES, Geisa Flores. Territórios, paisagens e representações: um diálogo em construção. Revista Mercator, Fortaleza, v. 10, n. 22, p. 23-35, mai./ago. 2011. Universidade Federal do Ceará.

A propósito do trato do invisível, do intangível e do discurso na Geografia Cultural. Revista da ANPEGE, v. 9, n. 11, p. 41-50, jan/jun. 2013. Associação Nacional de Pós-graduação e Pesquisa em Geografia.

ANDREOTTI, Giuliana. Geografia emocional e cultural, em comparação com a racionalista. In: HEIDRICH, Álvaro Luiz; COSTA, Benhur Pinós da; PIRES, Cláudia Luisa Zeferino (Orgs.). Maneiras de ler Geografia e Cultura. Porto Alegre: Imprensa Livre, 2013. p. 98-105.

BUTTIMER, Anne. Hogar, campo de movimento y sentido del lugar. In: GARCÍA RAMON, Ma․ D. Teoría y método en la geografia humana anglosajona. Barcelona: Ariel, 1985, pp. 227-241.

CLAVAL, Paul. A contribuição francesa ao desenvolvimento da abordagem cultural na geografia. In: CORRÊA, Roberto Lobato; ROSENDAHL, Zeny (Orgs). Introdução à geografia cultural. Rio de janeiro: Bertrand, 2003. p. 147-166.

FARIA, Andréa Alice da Cunha; FERREIRA NETO, Paulo Sérgio. Ferramentas do diálogo - qualificando 0 uso das técnicas do DRP: Diagnóstico Rural Participativo. Brasília: MMA; IEB, 2006.

FERREIRA, Luiz Felipe. Acepções recentes do conceito de lugar e sua importância para o mundo contemporâneo. Território, v. 9. jul./dez. 2000. p. 6583.

GARCIA CANCLINI, Néstor. Consumidores e cidadãos: conflitos multiculturais da globalização. 6ª ed. Rio de Janeiro: Editora UFRJ, 2006. 
HALL, Stuart. Da diáspora: identidades e mediações culturais. Belo Horizonte/Brasília: Editora UFMG/Unesco, 2006.

HOLZER, Werther. Um estudo fenomenológico da paisagem e do lugar: a crônica dos viajantes no Brasil do século XVI. 1998. Tese (Doutorado em Ciências: Geografia Humana) - Faculdade de Filosofia, Letras e Ciências Humanas, Universidade de São Paulo, São Paulo.

HOLZER, Werther. O lugar na geografia humanista. Território, v. 4, n 7, 1999, p.67-78.

LIMA, Nísia Trindade. Missões civilizatórias da República e interpretação do Brasil. História, Ciências, Saúde-Manguinhos, v. 5, 1998, p. 163-193.

MELLO, João Batista. Geografia Humanística: a perspectiva da experiência vivida e uma crítica radical ao positivismo. Revista Brasileira de Geografia, n.52, 1990, p. 91-115.

PROSHANSKY, H. M., FABIAN, A. K., KAMINOFF, R. Place identity: Physical world socialization of the self. Journal of Environmental Psychology, v.3, 1983, p.57-83.

RELPH, Edward. As bases fenomenológicas da Geografia. Revista Geografia, v. 4, n.7, 1979, p. 1-25.

SANTOS, Milton. A natureza do espaço: técnica e tempo, razão e emoção. São Paulo: Hucitec, 1996.

TERRA, Lygia. Geografia geral e geografia do Brasil: o espaço natural socioeconômico. São Paulo: Moderna, 2005.

TUAN, Yi-Fu. Place: an experiential perspective. Geographical Review, v. 65 n. 2, 1975, p. 151-165.

. Espaço e lugar: a perspectiva da experiência. São Paulo: Difel, 1983.

(Recebido em 29.06.2015; Aceito em: 14.03.2016) 